\title{
Research on Historical and Future Spatial-Temporal Variability of Precipitation in China
}

\author{
Jun Yin, ${ }^{1}$ Denghua Yan, ${ }^{1}$ Zhiyong Yang, ${ }^{1}$ Zhe Yuan, ${ }^{1}$ Yong Yuan, \\ Hao Wang, ${ }^{1}$ and Xiaoliang $\mathrm{Shi}^{3}$ \\ ${ }^{1}$ State Key Laboratory of Simulation and Regulation of Water Cycle in River Basin, Department of Water Resources, \\ China Institute of Water Resources and Hydropower Research, Beijing 100038, China \\ ${ }^{2}$ Division of International Cooperation, China Institute of Water Resources and Hydropower Research, Beijing 100038, China \\ ${ }^{3}$ College of Geomatics, Xian University of Science and Technology, Xian 710054, China
}

Correspondence should be addressed to Denghua Yan; yandh@iwhr.com and Zhiyong Yang; yangzy@iwhr.com

Received 4 May 2015; Revised 5 November 2015; Accepted 16 December 2015

Academic Editor: Christophe Cudennec

Copyright (C) 2016 Jun Yin et al. This is an open access article distributed under the Creative Commons Attribution License, which permits unrestricted use, distribution, and reproduction in any medium, provided the original work is properly cited.

\begin{abstract}
Based on observed data and data simulated by climate models, temporal variation and spatial distribution of precipitation in China from 1961 to 2050 were investigated. The slope of annual precipitation and Mann-Kendall statistical test were applied to quantify the trend magnitude and detect the significant trend, respectively. Besides, decadal and interannual variations of different rain belts were analyzed to reveal the spatial changing pattern of precipitation. Results indicated the following. (1) During 1961-2011, annual precipitation in Haihe River Basin decreased significantly while the annual precipitation in river basins in the northwest increased significantly. Although the annual precipitation of Yangtze River Basin has an indistinctive decreasing trend, that in the middle and lower reaches has increased and that in the upper reaches has decreased. Arid zone and humid zone are shrinking while semiarid and semihumid zone are expanding. Transformation between semiarid and arid zones, humid and semihumid zones is frequent. During 2011-2050, annual precipitation will not change much (-6 12\%) except river basins in the southwest (more than 40\%) compared with the baseline. Besides, the area of arid zone will decrease and humid zone area will increase. Transformation area between semiarid and arid zone and humid and semihumid zone is small.
\end{abstract}

\section{Introduction}

Precipitation is one of the key factors in climate system and hydrometeorology. In the context of climate change, due to changes in atmospheric circulation caused by increasing global surface temperature, pattern of precipitation and water-holding capacity throughout the atmosphere are very likely to change [1]. Overall, precipitation has increased by about $2 \%$ worldwide since the beginning of the 20th century $[2,3]$. The increase is statistically significant, though neither spatially nor temporally uniform $[4,5]$. Impacts of global warming on climatic system will continue in the near future. Arid region will receive even less precipitation while humid region will receive even more precipitation [6]. China is vulnerable to climate change impact and regional difference in precipitation is one of the major features of China's climatology. Changing trend of annual precipitation of China is not statistically significant in the recent 100 years and 50 years, but big decadal and interannual fluctuation exist [7]. Changes in precipitation pattern may lead to floods, droughts, and loss of biodiversity and agricultural productivity which will bring out even worse impacts on social economy of China [8]. Therefore, research on spatial and temporal changing trends of precipitation both in the present and in the future is important for water resources management and appropriate adaptation strategies making. Many studies have investigated the changing trends of precipitation in China. Liu et al. investigated the precipitation change in the Yellow River Basin (YRB) during 1960-2006 and it showed a decreasing trend in most of the precipitation stations [9]. The study performed by Chen et al. found that the precipitation variability was low in Yangtze River Basin and annual precipitation change was not statistically significant [10]. Liang et al. analyzed the precipitation variability in Northeast China from 1961 to 
2008 and the results showed that the annual precipitation decreased from the southeast to the northwest during the study period [11]. Even though these findings can help provide rational regulatory and managerial policy in relation to water resources to maintain the health of the various ecosystems, limitations still exist in the above studies. First of all, China has huge national territorial area and is located in several different climatic zones, mainly influenced by monsoon. Different climatic zones are controlled by different atmospheric circulation and are responding differently to global climate change. Recent studies mainly focus on specific basins of China, lacking systematic analysis on annual precipitation variation on nation scale. Secondly, most researches focus on historical change of precipitation; changing trend of projected precipitation in the context of future climate change has not attracted much attention. Nowadays, coupled climate models have become a strong basis for analysis and projection research on future precipitation under different emission scenarios. What is more, more attention has been paid to the temporal changing law of annual precipitation than spatial changing law. Less research on rain belts shifting characteristics has been done.

The objective of this paper is to analyze the long term (1961-2050) spatial and temporal trends of annual precipitation in China with the observed and simulated daily precipitation data. The slope of annual precipitation and MannKendall statistical test were applied to quantify the trend magnitude and detect the statistical significance of changing trend, respectively. By analyzing the decadal and interannual variation of four types of regions (humid zone, semihumid zone, semiarid zone, and arid zone), spatial changing characteristics of precipitation were illustrated. It is expected that this study will help understand regional hydrologic behavior over the last several decades and the near future in China.

\section{Materials and Methods}

2.1. Study Area. China is located in the east of Eurasia, west coast of the Pacific Ocean, subtropical zone of the north hemisphere, and midlatitude region. Due to land-sea thermal differences, pressure centers of upper and lower atmosphere change with the iteration of the four seasons. Besides, Tibet Plateau has great impact on the transmission of upper air. All these factors have resulted in the complex monsoon and different climate types in China. There are four climate zones from northwest to southeast: arid zone, semiarid zone, semihumid zone, and humid zone. There are ten big basins in China: Songhuajiang River Basin, Liaohe River Basin, Haihe River Basin, Yellow River Basin, Huaihe River Basin, Yangtze River Basin, river basins in the southeast, Pearl River Basin, river basins in the southwest, and river basins in the northwest (Figure 1).

Annual precipitation in China has an uneven spatial distribution. Precipitation features are significantly different between the north and the south. Annual mean precipitation is more than $800 \mathrm{~mm}$ in the basins of the south, in which Pearl River Basin and river basins in the southeast can receive more than $1500 \mathrm{~mm}$ of annual precipitation. Except for Liaohe River Basin, all the other basins in the north part of China

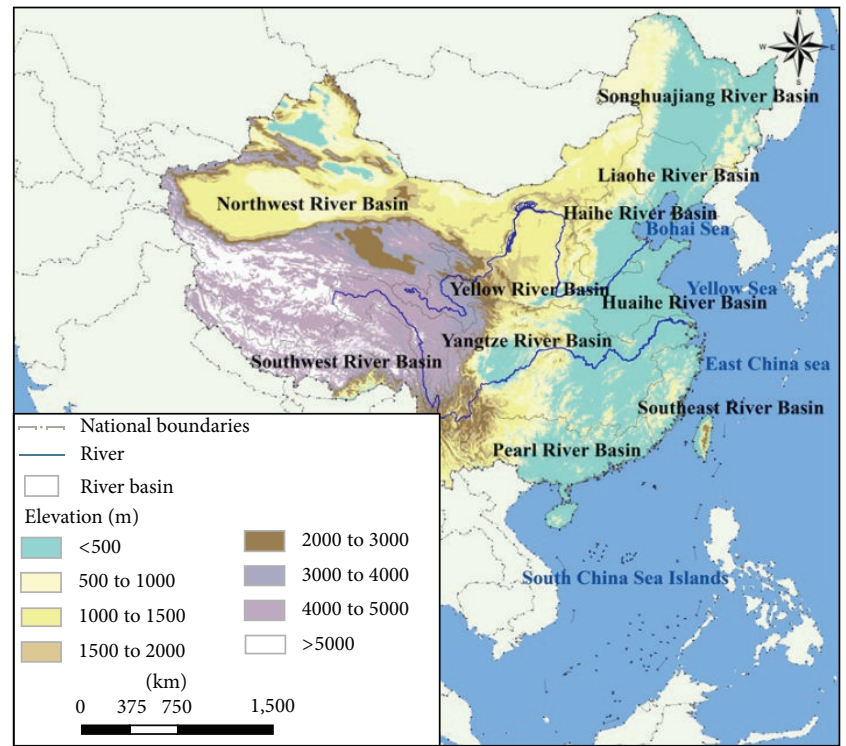

Figure 1: Location of China and ten big river basins in China.

receive less than $600 \mathrm{~mm}$ of annual precipitation. The annual precipitation of river basins in the northwest is the lowest, with only about $150 \mathrm{~mm}$. Difference of precipitation between different basins is one of the main reasons causing the uneven distribution of water resources of China.

2.2. Data. Observed precipitation data is selected from China's Ground Precipitation $0.5^{\circ} \times 0.5^{\circ}$ Gridded Dataset (V2.0) established by the Meteorological Records Office of the National Meteorological Information Center of China (http://www.cma.gov.cn/2011qxfw/2011qsigx/). This dataset is based on the daily precipitation records of 2474 national meteorological stations. Partial Thin Plate Smoothing Splines were used to do spatial interpolation $[12,13]$. In the meantime, impacts of topography on precipitation are also taken into consideration to make sure that the spatial distributions of interpolated precipitation and actual precipitation fit with each other [14] (Table 1).

Future daily precipitation of this research comes from five global climate models (GFDL-ESM2M, HadGEM2-ES, IPSL-CM5A-LR, MIROC-ESM-CHEM, and NorESM1-M) provided by ISI-MIP (Inter-Sectoral Impact Model Intercomparison Project) (http://www.isi-mip.org) $[15,16]$. Time range of precipitation data is from January 1, 2011, till December 31, 2050, and spatial resolution is $0.5^{\circ} \times 0.5^{\circ}$. This set of data was linearly interpolated and bias-corrected which is more accurate than the original data. This research selected scenario RCP4.5 (Representative Concentration Pathway 4.5) to analyze.

2.3. Precipitation Zoning. In China, $800 \mathrm{~mm}$ precipitation isoline goes from Qinling-Huaihe River to the southeast rim of Tibet Plateau. In the east and south side of this isoline, annual precipitation is usually more than $800 \mathrm{~mm}$ and this area is humid zone. In the west and north side of this isoline, annual precipitation is usually less than $800 \mathrm{~mm}$ and 
TABLE 1: List of general circulation models (GCMs) used in this study.

\begin{tabular}{lcc}
\hline Centre & Country & Name \\
\hline Geophysical Fluid Dynamics Laboratory (GFDL) & United States & GFDL-ESM2M \\
Hadley Centre for Climate Prediction and Research, Met Office & United Kingdom & HADGEM2-ES \\
L'Institut Pierre-Simon Laplace (IPSL) & France & IPSL-CM5A-LR \\
$\begin{array}{l}\text { Technology, Atmosphere and Ocean Research Institute and National Institute for } \\
\text { Environmental Studies }\end{array}$ & Japan & MIROC-ESM-CHEM \\
Norwegian Climate Centre & Norway & NORESM1-M \\
\hline
\end{tabular}

TABLE 2: Annual precipitation zoning.

\begin{tabular}{lcccc}
\hline Zoning number & I & II & III & IV \\
\hline Annual precipitation $(\mathrm{mm})$ & $<400$ & $400-600$ & $600-800$ & $\geq 800$ \\
\hline
\end{tabular}

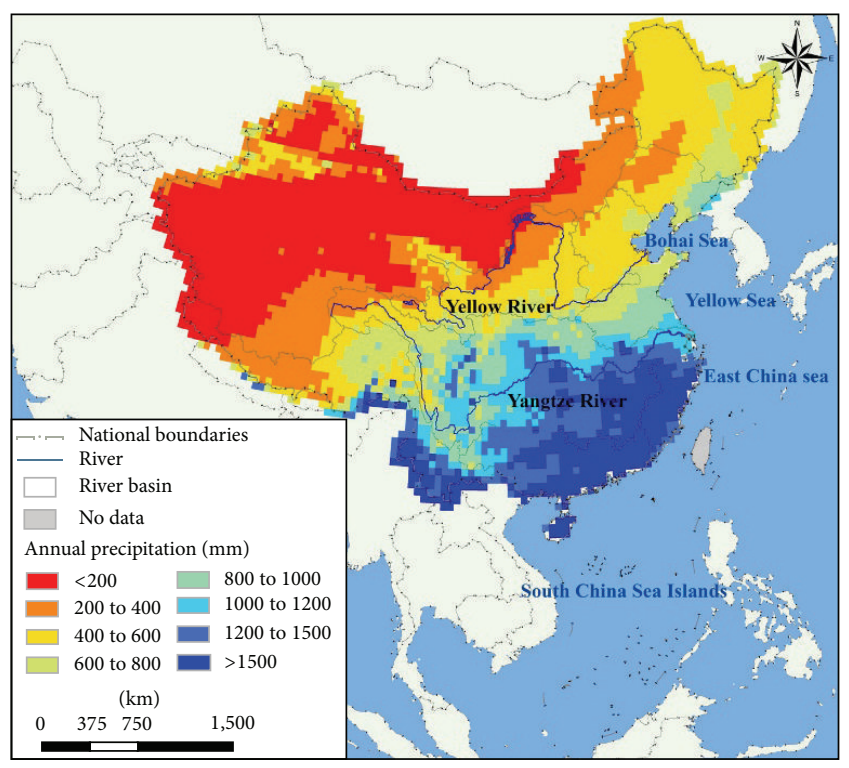

FIgURE 2: Multiyear average precipitation in China (1961-2011).

this area is semihumid zone. $800 \mathrm{~mm}$ precipitation isoline goes through Greater Khingan Range-Zhangjiakou-Lanzhou-Lhasa-east part of Himalaya Mountains, and this isoline is also the boundary between semihumid zone and semiarid zone. $200 \mathrm{~mm}$ precipitation isoline goes through the west part of Inner Mongolia Autonomous Region, west part of Hexi Corridor, and Northern Tibetan Plateau, and this isoline is also the boundary between arid zone and semiarid zone. According to annual precipitation, this paper divides China into four zones listed in Table 2. Temporal and spatial variation of historical and projected annual precipitation in each zone were analyzed (Figure 2).

2.4. Mann-Kendall Trend Test. Mann-Kendall (MK) statistical test [17] is used to analyze the changing trend and to test the significance. MK test is a nonparametric and rank-based approach. Compared with parametric methods, MK test is less sensitive to outliers. This method is widely used in the field of hydrology and climatology [18-20].
The test statistic $U$ was established:

$$
\begin{aligned}
U & =\frac{\tau}{\sqrt{V_{a r}(\tau)}}, \\
\tau & =\frac{4 p}{n(n-1)}-1, \\
V_{a r(\tau)} & =\frac{2(2 n+5)}{9 n(n-1)},
\end{aligned}
$$

where $n$ is the length of the data sequence and $p$ is the allelomorph of the random sequence. If $U$ is positive, the sequence has an increasing trend, if $U$ is negative, the sequence has a decreasing trend, and if $|U|>U \alpha=1.96$ while the significance level is $\alpha=0.05$, then the sequence has passed the significance test with a significant changing trend [21].

2.5. Linear Regression Analysis and the Slope. In this research, we use least-squares fitting method to estimate the magnitude of value in terms of linear trend. The linear trend of the data sequence can be calculated by this method and $y$ can be expressed by the linear regression equation as follows [22]:

$$
\hat{y}=a x+b,
$$

where $a$ is the estimated trend of data sequence. If $a>0$, it means that the value has an increasing trend in the study area during the study period, whereas if $a<0$, it means that the value in this area has a decreasing trend in the study area during the study period [23]. Parameter $a$ can be calculated via the following equation:

$$
a=\frac{n \times \sum_{i=1}^{n}\left(i \times K_{i}\right)-\sum_{i=1}^{n} i \sum_{i=1}^{n} K_{i}}{n \times \sum_{i=1}^{n} i^{2}-\left(\sum_{i=1}^{n} i\right)^{2}},
$$

where $n$ is the number of whole study years and $K_{i}$ is the value in the $i$ th year.

\section{Results and Discussion}

3.1. Temporal Variation of Historical Annual Precipitation. From the aspect of interannual variation (Figure 3), annual precipitation values in Songhuajiang River Basin, Liaohe River Basin, Haihe River Basin, Yellow River Basin, and Yangtze River Basin all show a decreasing trend, in which the decreasing trend of Haihe River Basin passed the significance test at $\alpha=0.1\left(\beta_{C}=-1.68<-1.65\right)$. The precipitation slope also reaches its negative peak in Haihe River Basin 

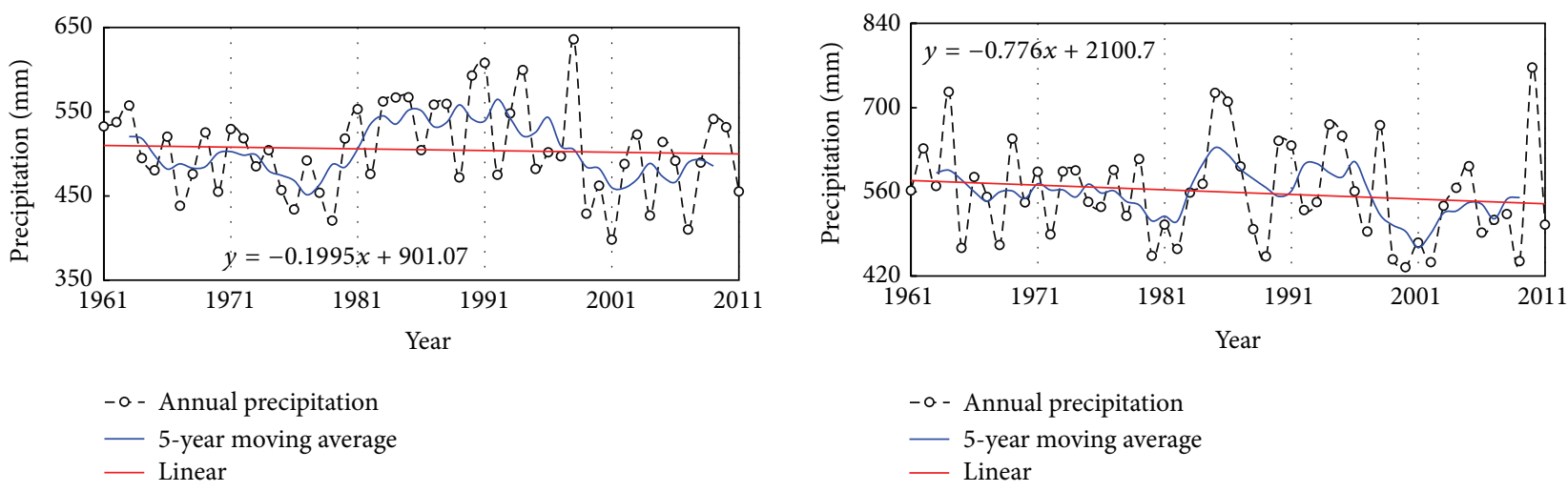

(a)

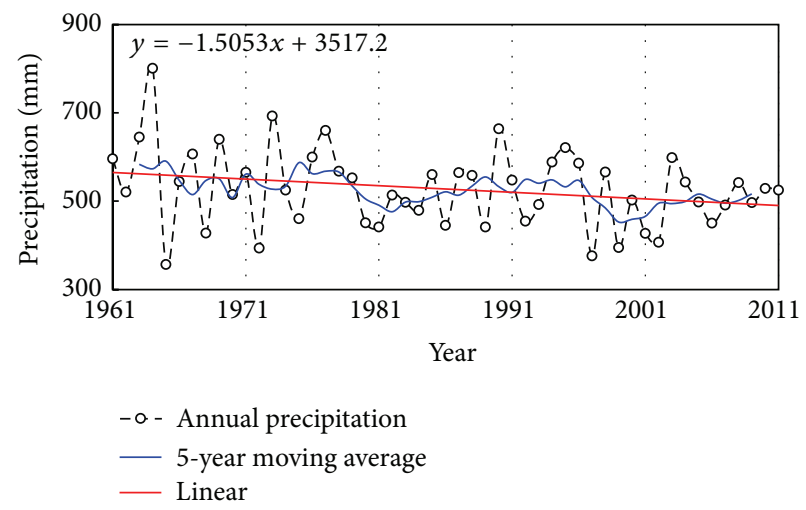

(c)

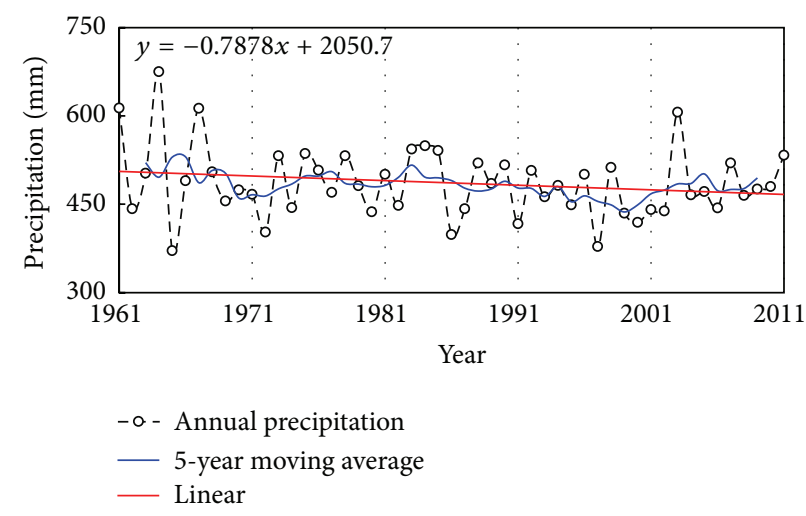

(d)
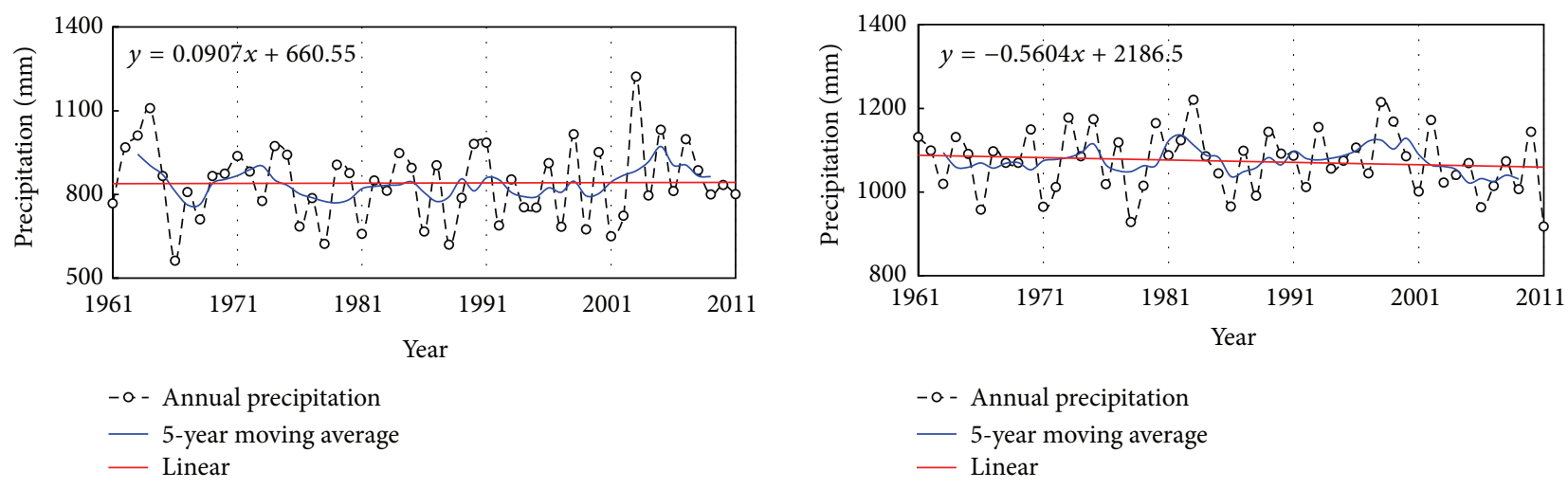

(e)
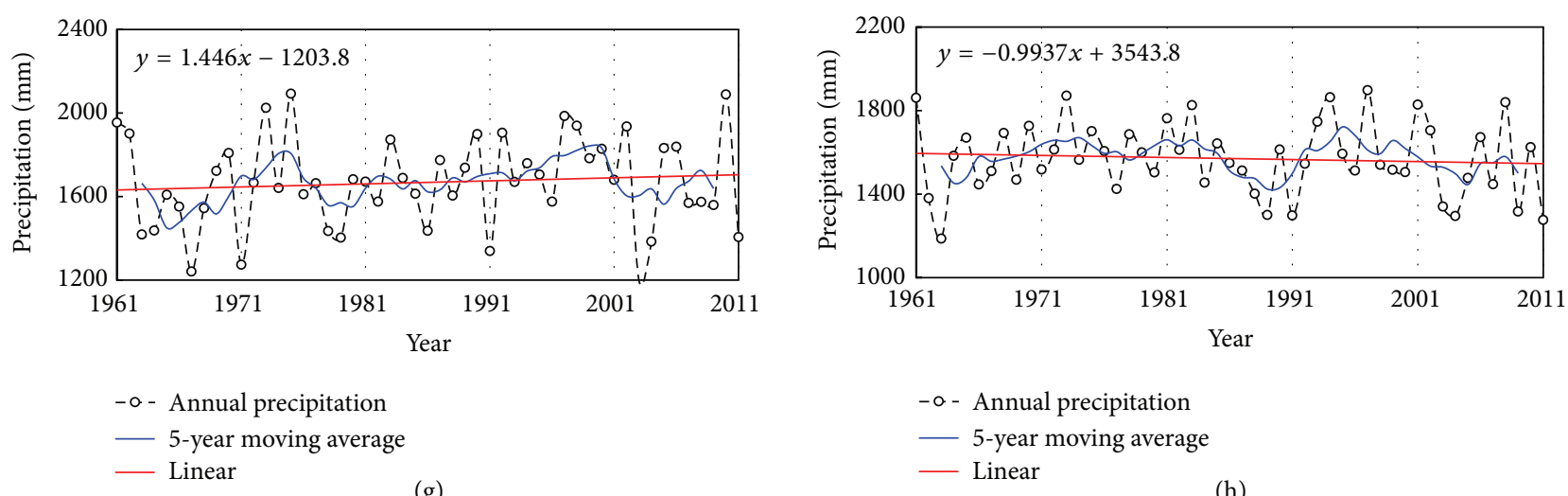

(g)

Figure 3: Continued. 

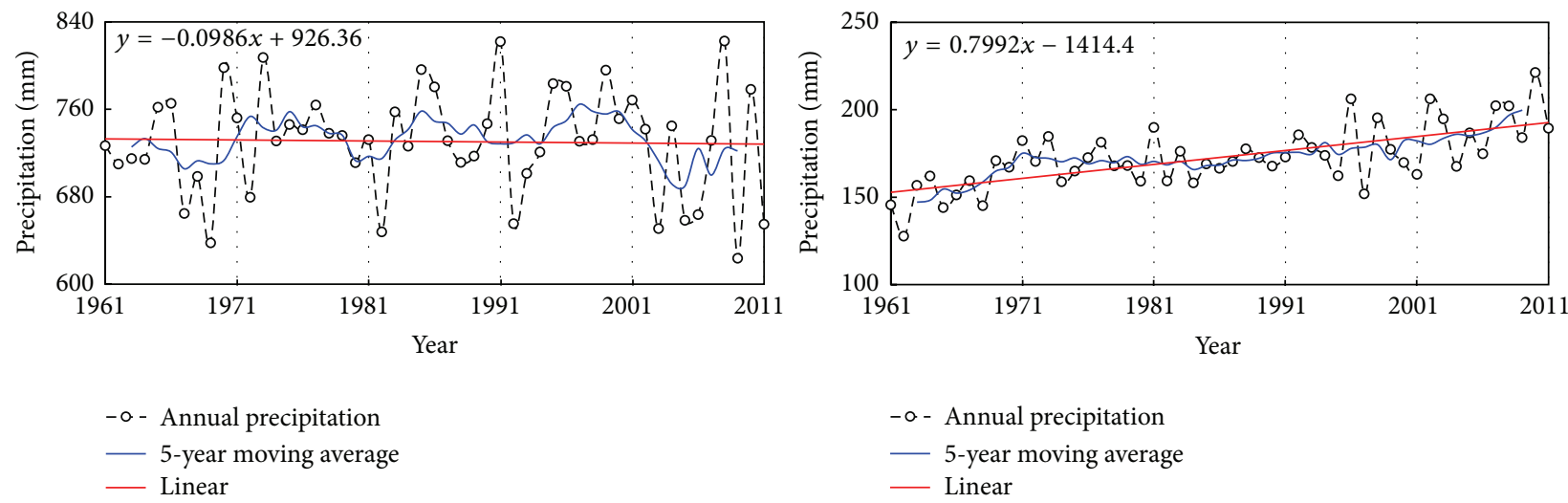

(i)

(j)

Figure 3: Annual precipitation of the top ten basins of China, 1961-2011. (a) (j) represent Songhuajiang River Basin, Liaohe River Basin, Haihe River Basin, Yellow River Basin, Huaihe River Basin, Yangtze River Basin, river basins in the southeast, Pearl River Basin, river basins in the southwest, and river basins in the northwest, similarly hereinafter.

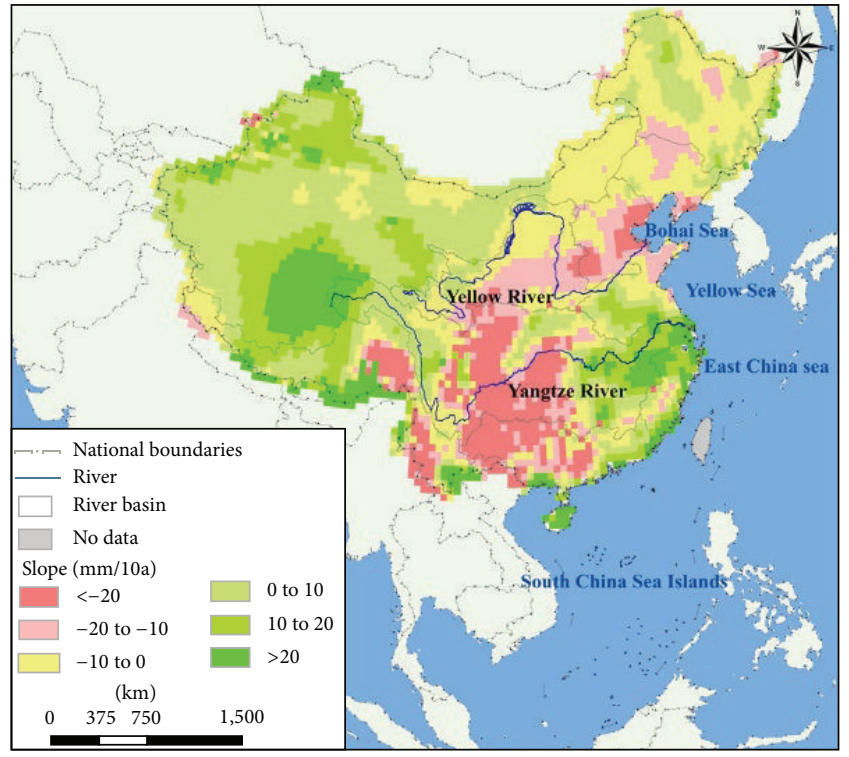

FIGURE 4: Changing slope of annual precipitation.

( $-15.0 \mathrm{~mm} / 10$ years). Annual precipitation values of Huaihe River Basin, river basins in the southeast, river basins in the southwest, and river basins in the northeast all show an increasing trend. Annual precipitation of river basins in the northwest has the most significant increasing trend $\left(\beta_{J}=4.88>1.96\right.$; passed the significance test at $\left.\alpha=0.05\right)$ and it is the only basin whose precipitation has increased in the north of China. The precipitation slope reaches its positive peak in river basins of the southeast ( $14.5 \mathrm{~mm} / 10$ years).

Figures 4 and 5 are the changing slope and trend test results of annual precipitation of China, 1961-2011. The two pictures show that the decreasing rate of annual precipitation is big in the plain area of Haihe River Basin, mountain area of Ziyahe River and Zhangweihe River, middle reaches of the Yangtze River, Nanpan River, and Beipan River of the Pearl River Basin, Yujiang River, and Liujiang River. The

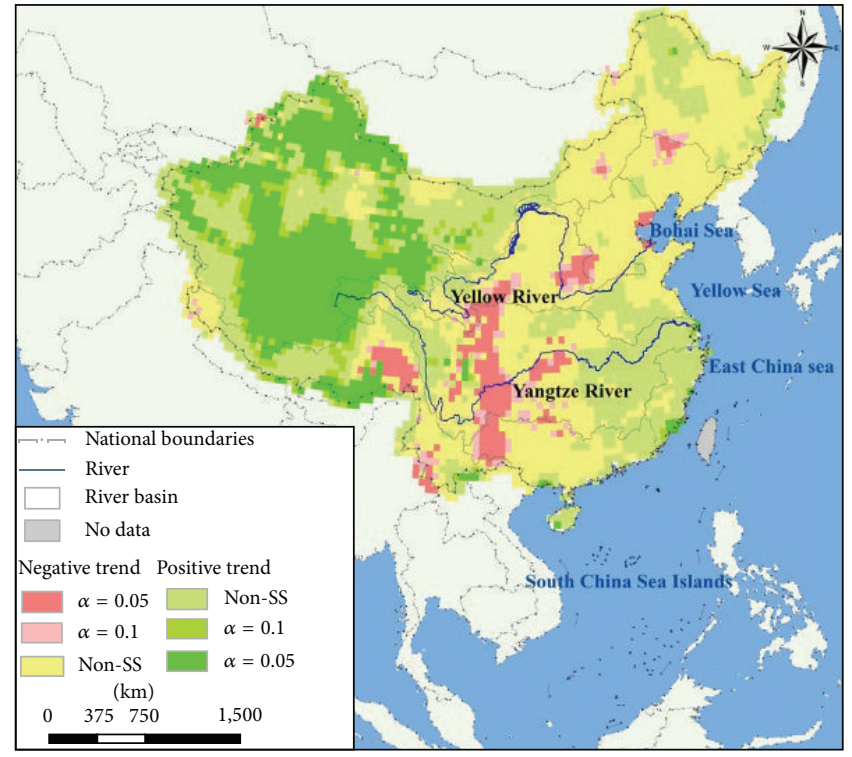

FIGURE 5: Trend test of annual precipitation.

decreasing rate in these areas can be more than $20 \mathrm{~mm} / 10 \mathrm{a}$. The decreasing trend in Mintuojiang River and Jialingjiang River of the Yangtze River Basin and the Nanpanjiang River and Beipanjiang River of the Pearl River Basin is statistically significant. The increasing trend is big in Qiangtang interior tableland of the river basins in the southwest and lower reaches of the Yangtze River Basin (such as the main stream below Hukou). The increasing trend in most areas of river basins in the southwest passed the significance test at $\alpha=0.1$.

3.2. Spatial Variation of Historical Precipitation. During 19612011, area of I IV was $25.09 \%, 18.38 \%, 28.62 \%$, and $27.91 \%$ of the total area of China. The area of I and IV decreased during the study and the decreasing trend in zone I has passed the significance test at $\alpha=0.05\left(\beta_{\mathrm{I}}=-3.63<-1.96\right)$. Areas of 

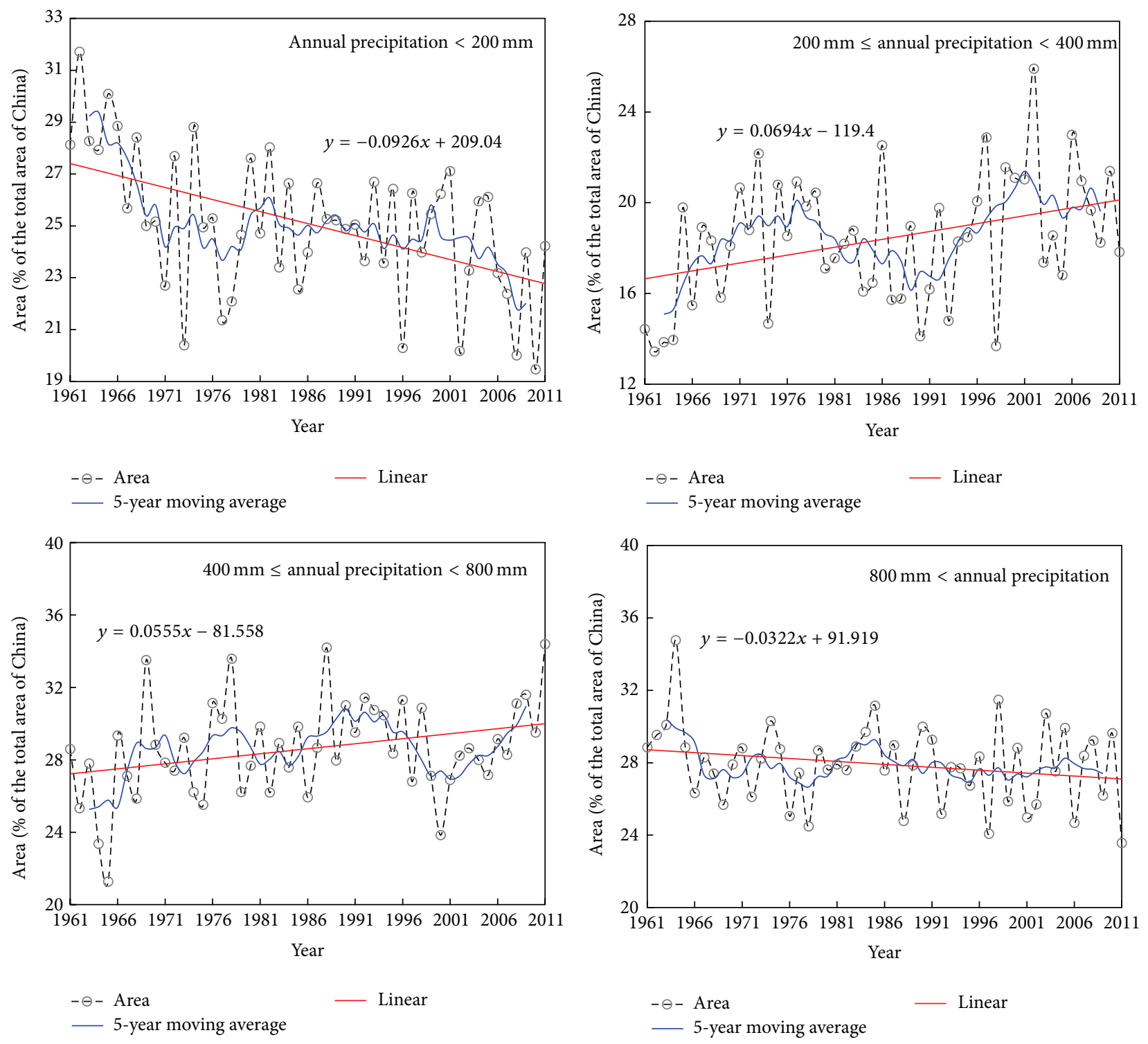

FIgURE 6: Interannual variation of area of different type of zone.

II and III are both increasing $\left(\beta_{\text {II }}=2.38>1.96, \beta_{\text {III }}=2.31>\right.$ 1.96) (Figure 6). So it can be seen that, during 1961-2011, the areas of arid zone and humid zone were shrinking while the areas of semiarid and semihumid zone were expanding. Transformation area between different types of zones in each decade was calculated (Figure 7). The results showed that the expansion of semiarid zone was caused by the transformation from arid zone to semiarid zone. Although some of the semihumid zones transformed into semiarid zones, the transformed area from humid zone to semihumid zone is much more than that, thus leading to the expansion of semihumid zone. It can thus be seen that, during 1961-2011, the north of China (arid zone, semiarid zone, and semihumid zone) was turning from arid to humid, while the south of China (humid zone) was turning from humid to arid.

In a certain phase, active area is the area where a certain class appeared one or more times. Figure 8 shows the spatial
TABLE 3: Change of stable area and active area in each decade (100\%).

\begin{tabular}{ccccccccc}
\hline \multirow{2}{*}{ Time } & \multicolumn{2}{c}{ Class I } & \multicolumn{2}{c}{ Class II } & \multicolumn{2}{c}{ Class III } & \multicolumn{2}{c}{ Class IV } \\
& S & A & S & A & S & A & S & A \\
\hline $1960 s$ & 20.1 & 15.0 & 1.9 & 36.2 & 6.3 & 39.5 & 20.1 & 19.0 \\
$1970 s$ & 16.0 & 17.6 & 1.6 & 39.8 & 7.1 & 41.0 & 19.4 & 17.4 \\
$1980 s$ & 16.6 & 17.2 & 1.4 & 39.2 & 7.3 & 38.6 & 21.6 & 15.8 \\
$1990 s$ & 16.7 & 16.3 & 2.1 & 38.6 & 7.4 & 39.2 & 20.6 & 16.4 \\
$2000 s$ & 15.2 & 16.9 & 1.8 & 40.3 & 6.9 & 41.0 & 19.8 & 16.9 \\
\hline
\end{tabular}

S means stable area; A means active area. The data in the table is the ratio (\%) between the area of stable area/active area and the whole area of China.

distribution of active area and stable area of each zone (types I IV) in each decade. Table 3 shows the active area and stable area of each zone (types I IV) in each decade. Analyzing Figure 8 and Table 3, it can be seen that, for zones I and IV, 

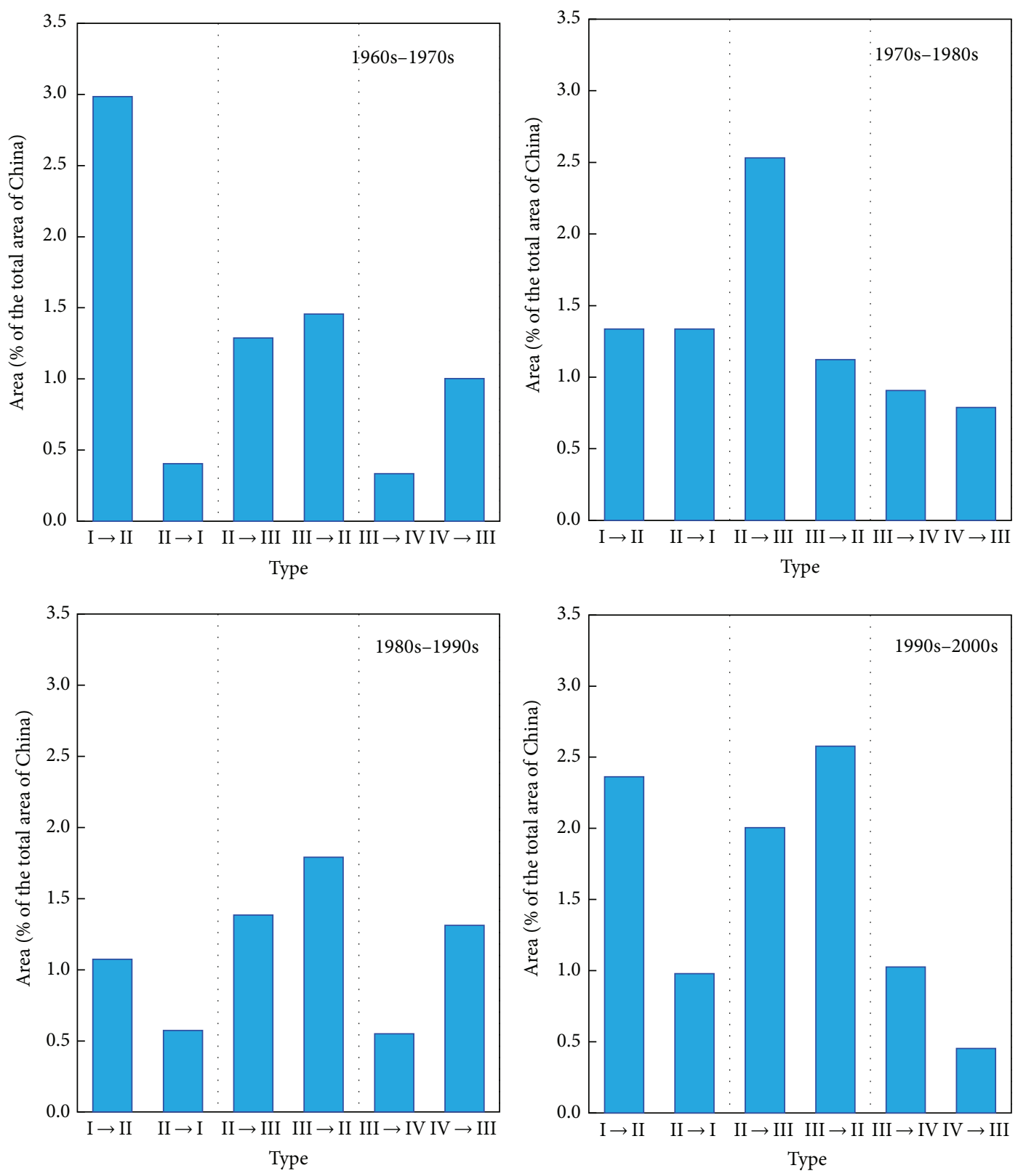

FIGURE 7: Transformation of each type of zone.

the ratio between stable area and active area stays at about $1: 1$. The stable area of zone I is mainly located at the Tarim region and Hexi Corridor region of river basins in the northwest. But since the 1970s, stable area of zone I began to decrease. The stable area of zone IV is mainly located at the south of Yangtze River. Although precipitation of the south of China decreased to some degree, the stable area always remains at $20 \%$ of the total area; that is, spatial distribution of precipitation in China (the north of China receives less precipitation while the south of China receives more precipitation) has not changed fundamentally. The stable area of zones II and III is comparatively small, which is about $1.8 \%$ and $7.0 \%$ of the total area of China, respectively, while the active area of zones II and III is $38.8 \%$ and $39.9 \%$ of the total area of China. As a result, the areas of semiarid zone and semihumid zone in the south of Yinshan Mountain and Qilianshan Mountain, east of Great Khingan, and north of Qinling Mountains have large interannual change.

3.3. Temporal Variation of Future Precipitation. In RCP4.5, future precipitation in each basin was projected by GFDLESM2M, HadGEM2-ES, IPSL-CM5A-LR, MIROC-ESMCHEM, and NorESM1-M and it was shown in Figure 9. Compared with the annual precipitation of baseline (1961 1990), annual precipitation in river basins of the northwest will have the largest decrease $(-12.9 \sim-1.1 \%)$, while that in river basins of the southwest will have the largest increase (42.4 50.4\%). For Songhuajiang River Basin, Huaihe River Basin, and river 

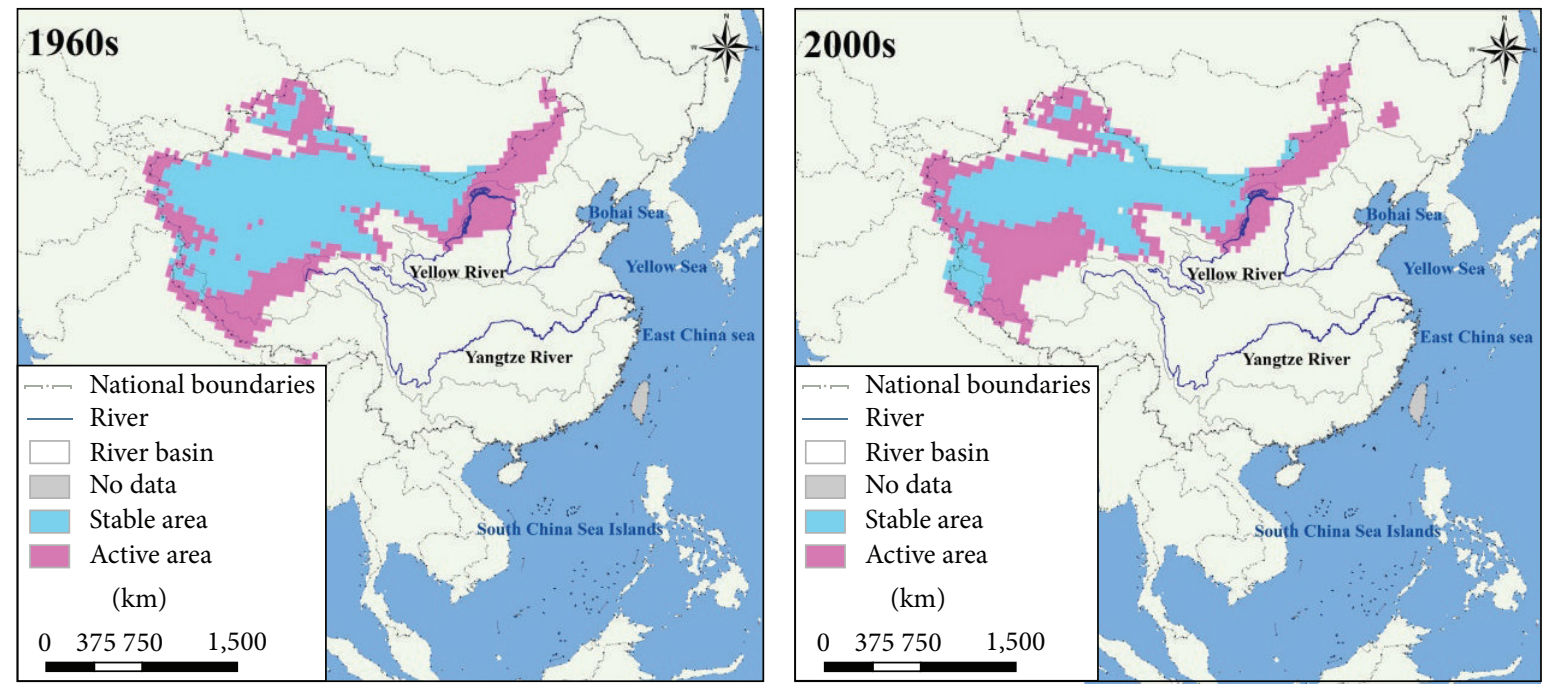

(a) Class I
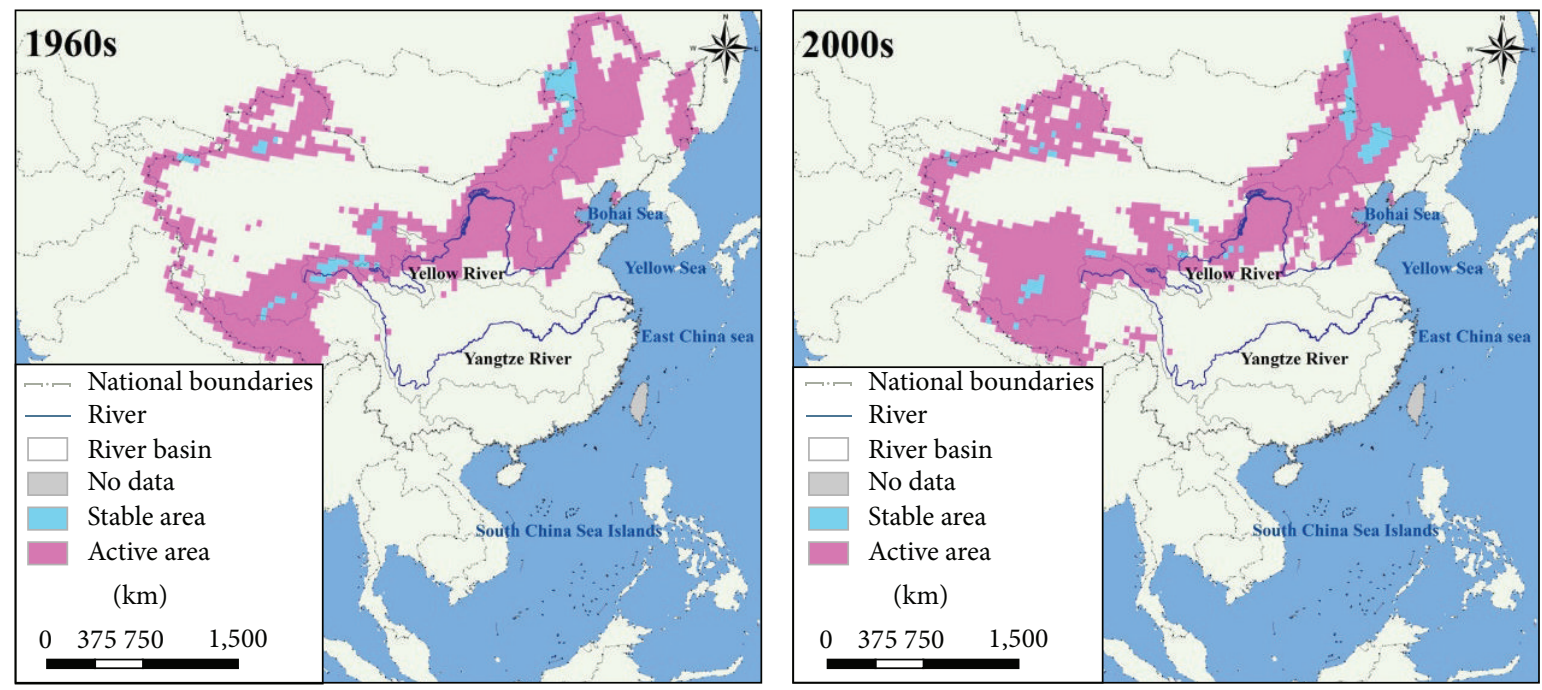

(b) Class II
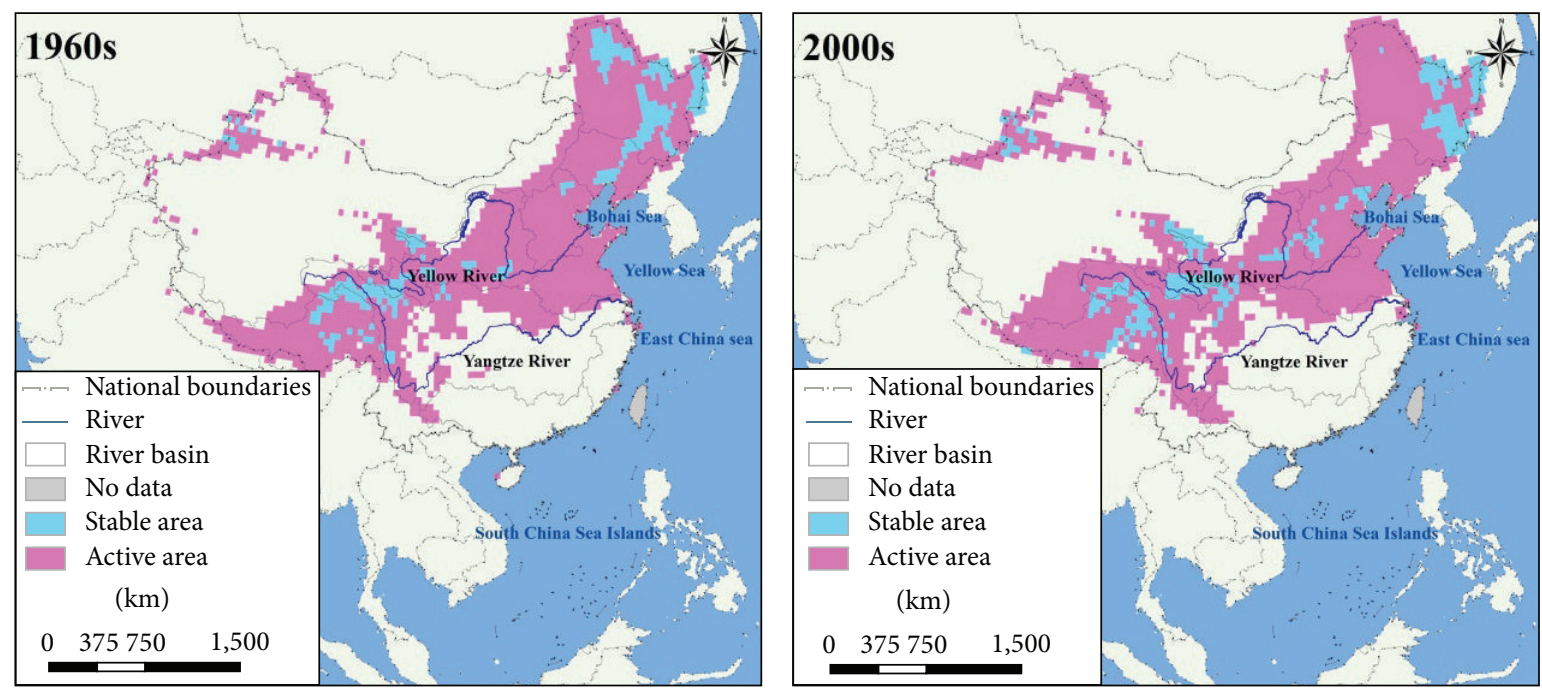

(c) Class III

Figure 8: Continued. 

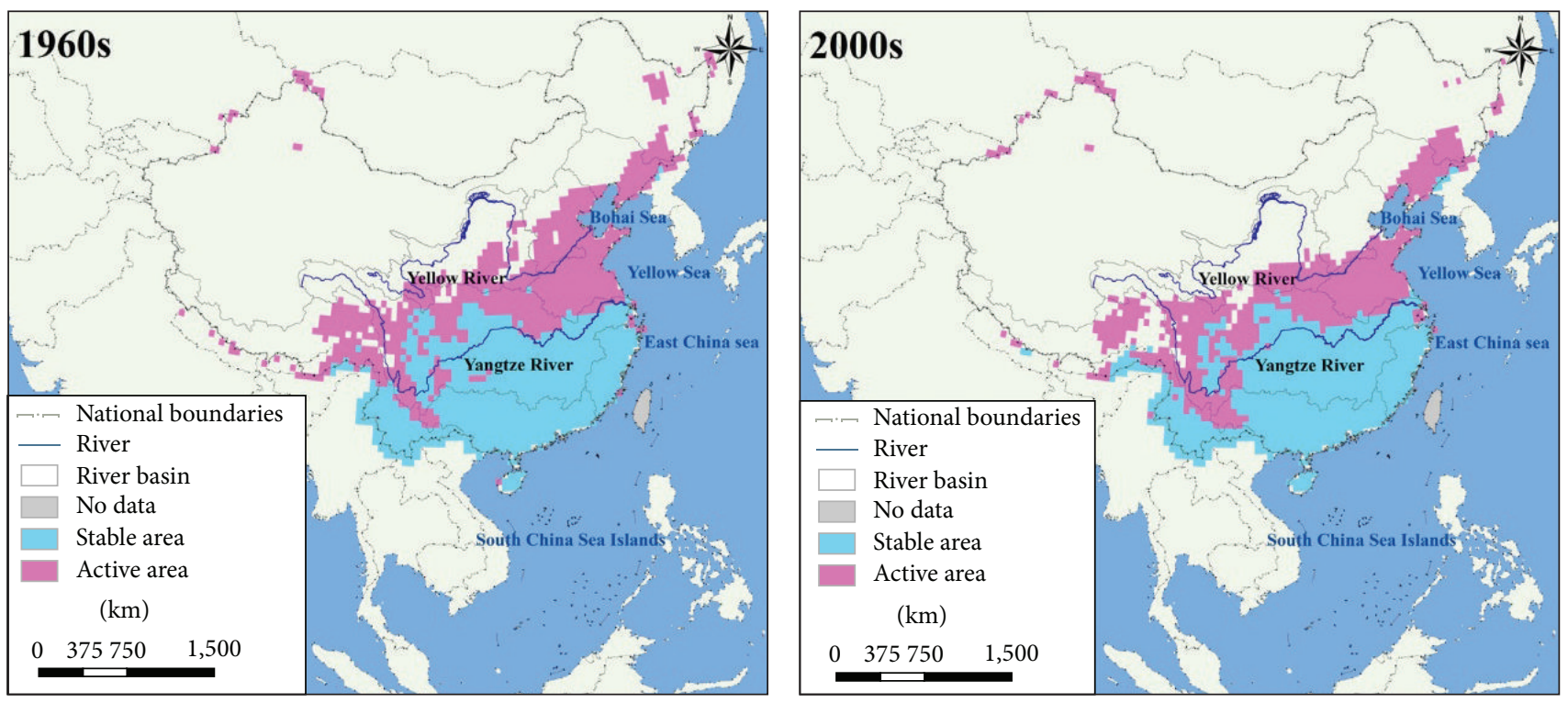

(d) Class IV

FIGURE 8: Decadal spatial movement characteristics of active area and stable area of different classes.

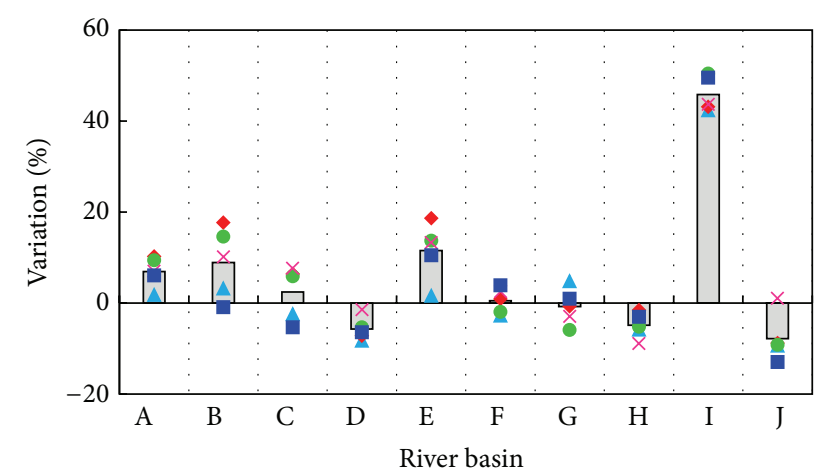

$\begin{array}{ll}\square \text { Mean } & \times \text { MIROC-ESM-CHEM } \\ - \text { IPSL-CM5A-LR } & \bullet \text { HadGEM2-ES } \\ \triangle \text { GFDL-ESM2M } & \square \text { NorESM1-M }\end{array}$

FIGURE 9: Projected annual precipitation of each basin. Songhuajiang River Basin (A), Liaohe River Basin (B), Haihe River Basin (C), Yellow River Basin (D), Huaihe River Basin (E), Yangtze River Basin $(F)$, river basins in the southeast $(\mathrm{G})$, Pearl River Basin $(\mathrm{H})$, river basins in the southwest (I), and river basins in the northwest (J).

basins in the southwest, all five climate models projected that the precipitation will increase. The mean increase values of five climate models are $6.9 \%, 11.6 \%$, and $45.9 \%$, respectively, for these three basins. For the Yellow River Basin and Pearl River Basin, all five climate models projected that the precipitation will decrease. The mean decrease values of five climate models are $-5.7 \%$ and $-4.9 \%$, respectively. For Liaohe River Basin and river basins in the northwest, projected annual precipitation will change by $9.0 \%$ and $-7.8 \%$ (mean value of five climate models), respectively (four climate models have the concordant result except for one climate model).
Projected annual precipitation in Haihe River Basin, Yangtze River Basin, and river basins in the southeast differs with different climate models, having big uncertainty. On the whole, except for river basins in the southwest, projected annual precipitation will not change a lot in other basins. The mean value of changing range is about $-6 \sim 12 \%$.

Figure 10 shows the projected annual precipitation distribution of different climate models. Annual precipitation in the northwest and southwest will change a lot: the annual precipitation in Tarim River Basin will decrease by more than $25 \%$ while that in Qiangtang interior plateau, Brahmaputra River Basin, and southern Tibet area will increase by more than 25\%. Annual precipitation in Northeast China, North China, Central China, and South China will have smaller $(-25 \sim 25 \%)$ change in most places.

3.4. Spatial Variation of Future Annual Precipitation. With the baseline of 1961-1990, the projected area change of each class was analyzed. It can be seen from Figure 11 that different climate models will result in different projections: only in a few years will the five selected climate models have accordant projections. The assembled mean value of multimodels shows that the area of zone II will have a decreasing trend to some degree while the area of zone IV will have an increasing trend to some degree. Table 4 shows the change of multiyear annual mean area of each type of zone during 2011-2050 compared with that of the baseline. The multiyear annual mean area of zone II will decrease by $6.13 \%$ compared with that of the baseline while the multiyear annual mean area of zone IV will increase by $4.47 \%$. That is to say, the area of semiarid zone will decrease to some degree while the area of humid zone will increase to some degree. Different climate models have different projections on the area change of zone I and zone III. 

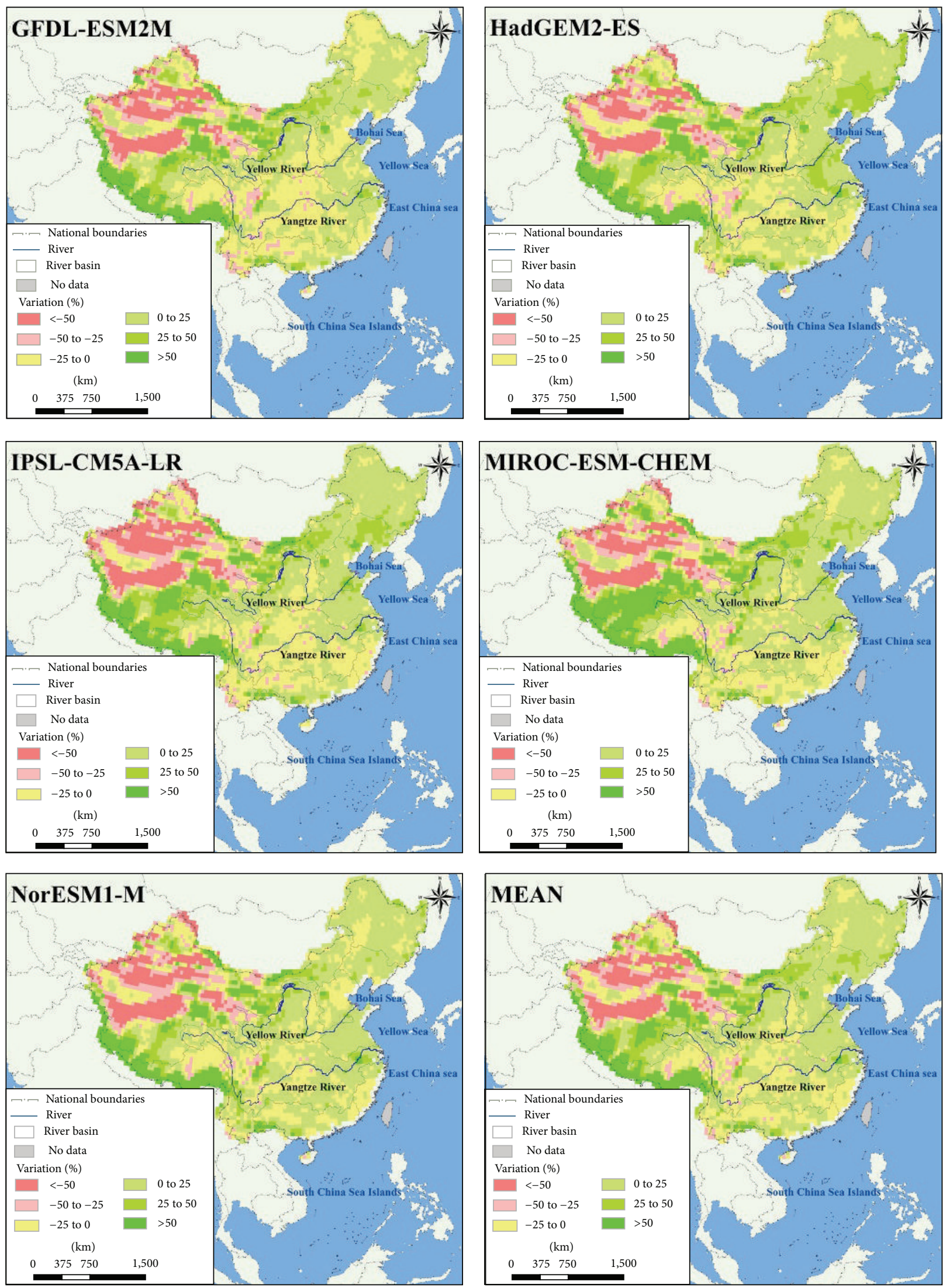

FIGURE 10: Projected annual precipitation distribution of different climate models. 

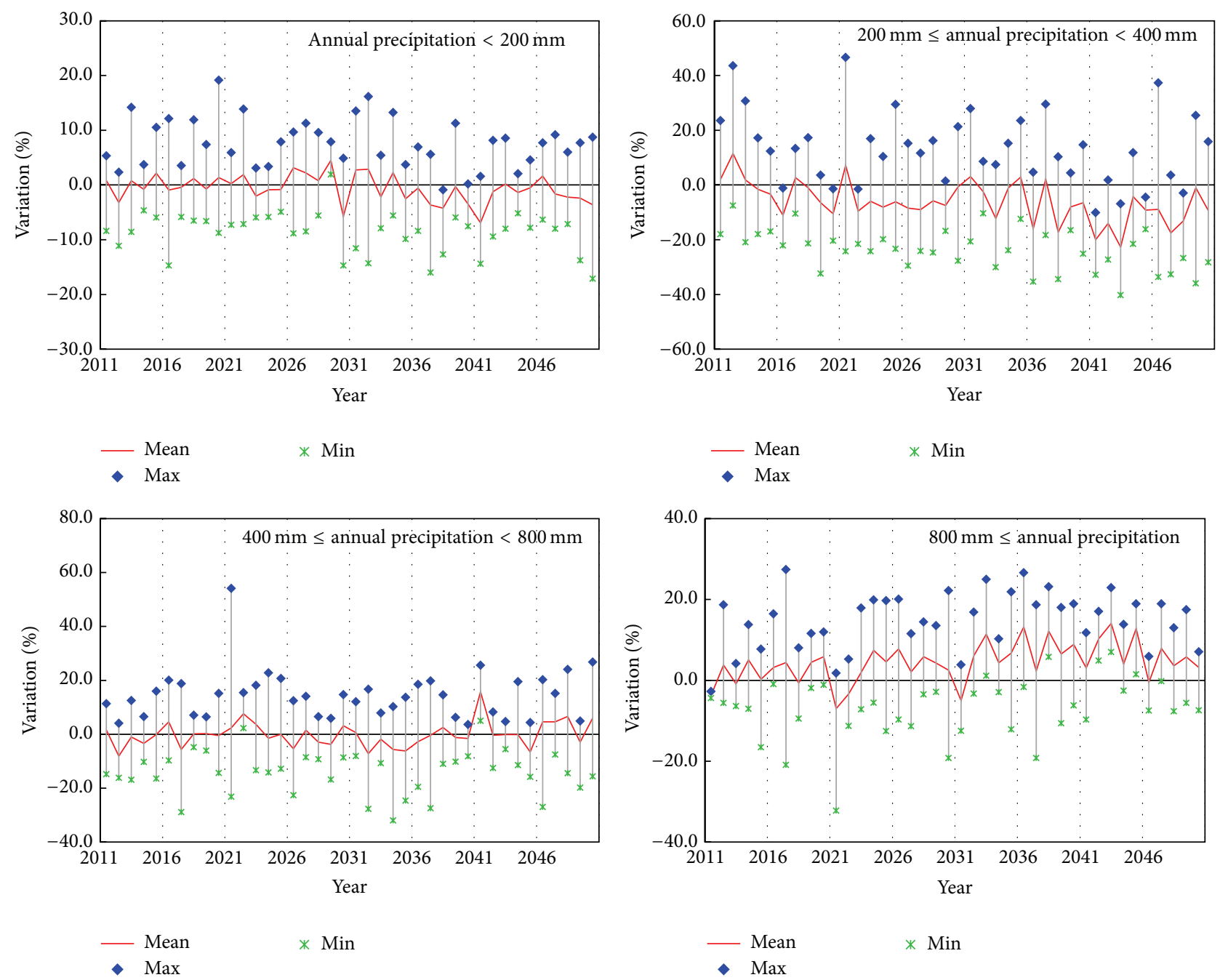

FIGURE 11: Interannual variation of projected area of each type of zone.

TABLE 4: Change of projected multiyear mean value of each type of zone compared with that during 1961-1990 (\%).

\begin{tabular}{|c|c|c|c|c|c|c|}
\hline Class & GFDL-ESM2M & HadGEM2-ES & IPSL-CM5A-LR & MIROC-ESM-CHEM & NorESM1-M & Mean \\
\hline I & -0.74 & 0.78 & 1.21 & -6.13 & 1.92 & -0.59 \\
\hline II & -1.92 & -1.20 & -14.40 & -10.79 & -2.33 & -6.13 \\
\hline III & 4.07 & -8.22 & 2.05 & 7.01 & -5.39 & -0.10 \\
\hline IV & -2.19 & 8.24 & 5.84 & 5.37 & 5.08 & 4.47 \\
\hline
\end{tabular}

Spatial distribution of stable area and active area of zones I IV during the projection period is similar to that during 1960s 2000s: the stable areas of zone I and zone IV are mainly located in the river basins of the southwest and south of Yangtze River, respectively; the stable area of zone II and zone III is comparatively small. During the projection period, the decadal mean value of the stable area of four types of zones will increase to a certain degree compared with the baseline (decadal mean value of 1960s 1990s). The stable areas of zone I, zone II, and zone III will increase by $12.5 \sim 27.1 \%$,
77.6 200.3\%, and 8.6 69.0\%, respectively, and all the five selected climate models have got concordant results. The stable area of zone IV will change by $-6.3 \sim 17.0 \%$ compared with that of the baseline in which only GFDL-ESM2M gave decreasing results while other models gave increasing results (Table 5). The increase of stable area in zone I means that the projected annual precipitation in the northwest of China will have persistently low precipitation. Although the stable areas of zone II and zone IV have big relative increase, the absolute increase is not big because the stable area is small 
TABLE 5: Decadal change of stable area and active area of each type of zone simulated by different climate models.

\begin{tabular}{|c|c|c|c|c|c|c|c|c|c|c|c|c|c|}
\hline \multirow{2}{*}{ Class } & \multirow{2}{*}{ Time } & \multicolumn{2}{|c|}{ M1 } & \multicolumn{2}{|c|}{ M2 } & \multicolumn{2}{|c|}{ M3 } & \multicolumn{2}{|c|}{ M4 } & \multicolumn{2}{|c|}{ M5 } & \multicolumn{2}{|c|}{ Mean } \\
\hline & & $S$ & A & $S$ & $\mathrm{~A}$ & $S$ & A & $S$ & A & $S$ & A & $S$ & A \\
\hline \multirow{4}{*}{ I } & $2010 \mathrm{~s}$ & 18.3 & 13.7 & 21.8 & 8.3 & 21.9 & 9.6 & 21.3 & 6.5 & 21.1 & 13.1 & 20.9 & 10.2 \\
\hline & $2020 \mathrm{~s}$ & 20.0 & 12.9 & 20.9 & 9.9 & 20.5 & 11.8 & 21.5 & 7.9 & 22.0 & 9.4 & 21.0 & 10.4 \\
\hline & 2030 s & 18.4 & 13.8 & 21.8 & 11.1 & 20.4 & 12.0 & 20.6 & 7.8 & 20.7 & 9.7 & 20.4 & 10.9 \\
\hline & $2040 \mathrm{~s}$ & 19.3 & 13.1 & 21.4 & 9.4 & 21.2 & 8.7 & 20.1 & 7.1 & 21.6 & 10.6 & 20.7 & 9.8 \\
\hline \multirow{4}{*}{ II } & $2010 \mathrm{~s}$ & 3.1 & 35.3 & 6.1 & 27.2 & 3.9 & 26.0 & 6.6 & 24.2 & 2.8 & 30.7 & 28.7 & 4.5 \\
\hline & 2020 s & 3.8 & 31.3 & 3.7 & 31.0 & 3.7 & 30.9 & 4.8 & 24.3 & 6.1 & 27.5 & 29.0 & 4.4 \\
\hline & $2030 \mathrm{~s}$ & 2.9 & 34.9 & 4.8 & 29.8 & 3.2 & 28.8 & 4.8 & 28.9 & 5.7 & 27.7 & 30.0 & 4.3 \\
\hline & $2040 \mathrm{~s}$ & 2.6 & 30.4 & 5.5 & 29.4 & 3.6 & 22.5 & 4.8 & 22.9 & 2.9 & 28.0 & 26.6 & 3.9 \\
\hline \multirow{4}{*}{ III } & $2010 \mathrm{~s}$ & 9.5 & 38.2 & 9.6 & 31.5 & 12.4 & 33.5 & 10.4 & 32.8 & 9.0 & 31.7 & 10.2 & 33.5 \\
\hline & $2020 \mathrm{~s}$ & 12.3 & 32.6 & 6.9 & 36.4 & 6.9 & 36.8 & 12.8 & 39.0 & 7.9 & 30.7 & 9.4 & 35.1 \\
\hline & $2030 \mathrm{~s}$ & 9.8 & 39.3 & 5.9 & 34.3 & 8.2 & 39.7 & 10.3 & 34.8 & 9.6 & 31.5 & 8.7 & 35.9 \\
\hline & $2040 \mathrm{~s}$ & 8.8 & 37.3 & 8.1 & 32.6 & 14.1 & 31.4 & 13.8 & 29.6 & 13.3 & 27.8 & 11.6 & 31.7 \\
\hline \multirow{4}{*}{ IV } & $2010 \mathrm{~s}$ & 18.1 & 18.6 & 22.8 & 14.2 & 19.6 & 16.9 & 22.4 & 15.7 & 22.8 & 15.4 & 21.1 & 16.2 \\
\hline & $2020 \mathrm{~s}$ & 19.3 & 13.5 & 23.3 & 17.9 & 22.1 & 17.5 & 14.1 & 22.8 & 24.4 & 12.7 & 20.6 & 16.9 \\
\hline & $2030 \mathrm{~s}$ & 17.8 & 18.0 & 23.4 & 17.9 & 18.7 & 22.4 & 22.3 & 16.6 & 23.2 & 15.1 & 21.1 & 18.0 \\
\hline & $2040 \mathrm{~s}$ & 21.0 & 19.7 & 23.8 & 14.1 & 21.8 & 17.6 & 24.7 & 13.7 & 24.7 & 9.7 & 23.2 & 15.0 \\
\hline
\end{tabular}

M1 M5 represent GFDL-ESM2M, HadGEM2-ES, IPSL-CM5A-LR, MIROC-ESM-CHEM, and NorESM1-M, respectively.

itself. The increase of the stable area of zone IV means that the precipitation of the south of China will be at a high level (Figure 12).

\section{Conclusions}

Based on the observed precipitation data during 1961-2011 and projected data of climate models during 2011-2050, this paper analyzed the spatial variation of historical and future precipitation.

During 1961-2011, precipitation in Haihe River Basin decreased significantly. What is more, socioeconomic development also added great pressure on the water demand in Haihe River Basin. These two factors caused the imbalance between water supply and water demand, leading to a series of problems of aquatic ecology and environment. Annual precipitation in the Yangtze River Basin decreased but not statistically significant. However, significant difference between the upper reaches and lower reaches occurred in Yangtze River. In the middle and lower reaches of the Yangtze River, annual precipitation has increased widely; the annual precipitation in the upper reaches has decreased a lot and the decreasing trend was statistically significant in most places. This could bring about negative effects on the ecosystem in the upper reaches of Yangtze River, which could bring about further negative impacts on the establishment of ecological barrier in the upper reaches. River basin in the northwest is the only basin in the north of China where the annual precipitation has increased. Undoubtedly, this will do good to the improvement of ecoenvironment in the northwest of China. Besides, arid zone and humid zone are shrinking while the semiarid zone and semihumid zone are expanding: area of semiarid zone and semihumid zone in the south of Yinshan
Mountain and Qilian Mountain, east of Great Khingan, and north of Qinling Mountains had big decadal variation. That is to say, the transition between semiarid zone and arid zone and humid zone and semihumid zone was more frequent in the climate transition zone.

In the scenario RCP4.5, annual precipitation in the ten big basins of China will not change much except for river basins in the southwest. Annual precipitation in the river basins in the northwest will decrease to a large degree with significant regional difference: annual precipitation will have increasing trend in the river district of interior zone of Inner Mongolia, river district of interior zone of Hexi, and interior zone of Qiangtang Plateau while the annual precipitation will have decreasing trend in the Tarim River Basin. River basins in the southwest will have large increase of annual precipitation, especially in the Brahmaputra River and southern Tibet. Different climate models have different projections. Projections in the Songhuajiang River Basin, Huaihe River Basin, and river basins in the southwest have good concordance: all five climate models gave increasing projections. On the contrary, climate models have big uncertainty in Haihe River Basin, Yangtze River Basin, and river basins in the southeast. The area of semiarid zone will decrease and the area of humid zone will increase to some degree in the future. Besides, spatial distribution of stable area and active area in each type of zone will remain similarly as in the past. The stable area in all the four types of zones will increase to some degree compared with the baseline; that is, the transition area between semiarid zone and arid zone and humid and semihumid zone in the climate transition area will not be big in the future. Arid zone may see more dry days while the humid zone may see more humid days. 

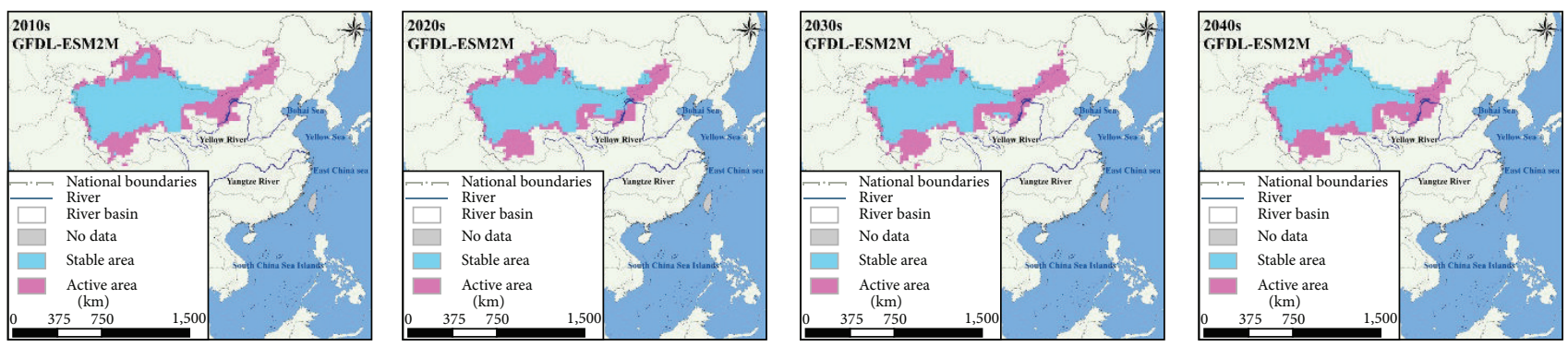

(a) Class I
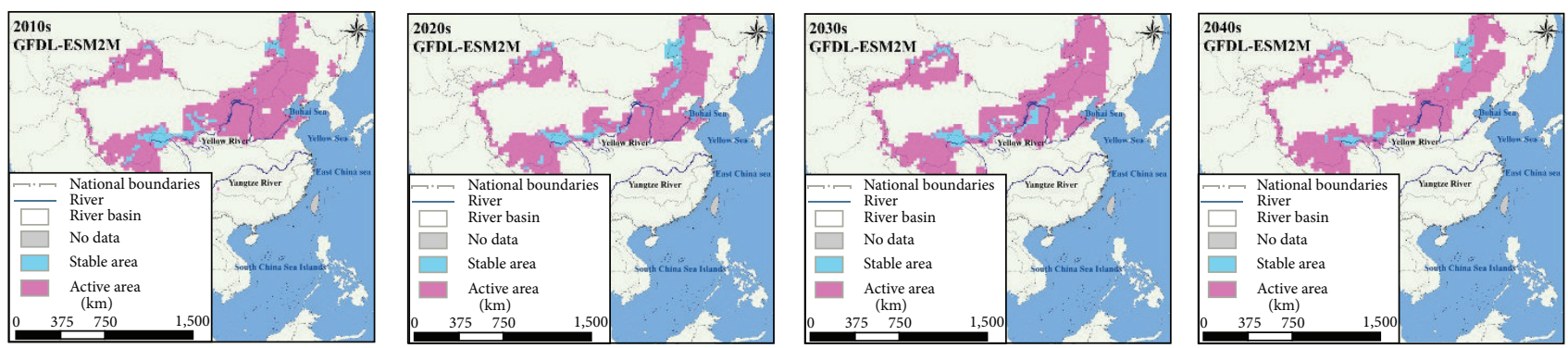

(b) Class II
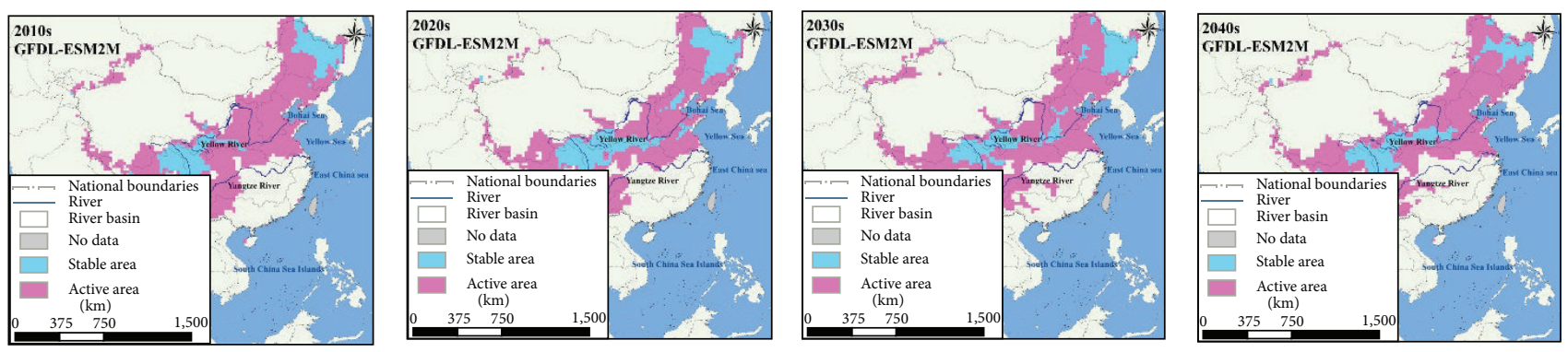

(c) Class III
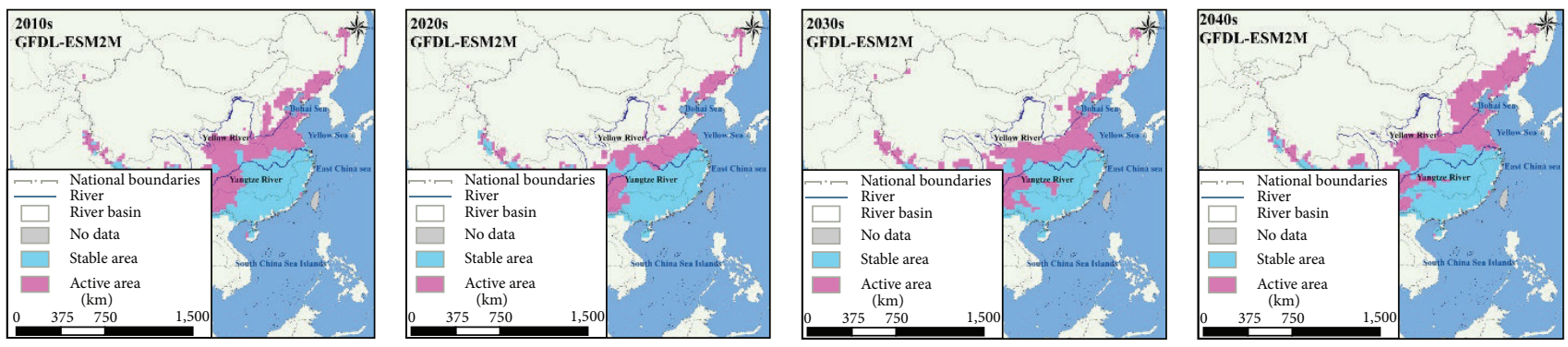

(d) Class IV

FIgURE 12: Projected stable area and active area in different decades.

\section{Conflict of Interests}

The authors declare that there is no conflict of interests regarding the publication of this paper.

\section{Acknowledgments}

This research was financially supported by the National Science-Technology Support Plan Projects "Technology Development and Application of Climate Change Impact and Risk Assessment in Key Field, Assessment Technology of Impact and Risk on Water Resources of Climate Change" (Grant no. 2012BAC19B03); General Program of the National Natural Science Foundation of China (Grant no. 51279207); Outstanding Youth Science Foundation of China (Grant no. 51522907); the National Natural Science Foundation of China (Grant no. 51409204).

\section{References}

[1] M. H. I. Dore, "Climate change and changes in global precipitation patterns: what do we know?" Environment International, vol. 31, no. 8, pp. 1167-1181, 2005. 
[2] P. D. Jones and M. Hulme, "Calculating regional climatic time series for temperature and precipitation: methods and illustrations," International Journal of Climatology, vol. 16, no. 4, pp. 361-377, 1996.

[3] M. Hulme, "Recent climatic change in the world's drylands," Geophysical Research Letters, vol. 23, no. 1, pp. 61-64, 1996.

[4] T. R. Karl and R. W. Knight, "Secular trends of precipitation amount, frequency, and intensity in the United States," Bulletin of the American Meteorological Society, vol. 79, no. 2, pp. 231-241, 1998.

[5] R. M. Doherty, M. Hulme, and C. G. Jones, "A gridded reconstruction of land and ocean precipitation for the extended tropics from 1974 to 1994," International Journal of Climatology, vol. 19, no. 2, pp. 119-142, 1999.

[6] IPCC, Climate Change 2013: The Physical Science Basis, Cambridge University Press, New York, NY, USA, 2013.

[7] Y. H. Ding, G. Y. Ren, G. Y. Shi et al., "National assessment report of climate change (I): climate change in China and its future trend," Advances in Climate Change Research, vol. 2, no. 1, pp. 3-8, 2006 (Chinese).

[8] M. Sayemuzzaman and M. K. Jha, "Seasonal and annual precipitation time series trend analysis in North Carolina, United States," Atmospheric Research, vol. 137, pp. 183-194, 2014.

[9] Q. Liu, Z. Yang, and B. Cui, "Spatial and temporal variability of annual precipitation during 1961-2006 in Yellow River Basin, China," Journal of Hydrology, vol. 361, no. 3-4, pp. 330-338, 2008.

[10] J. Chen, X. D. Wu, B. L. Finlayson et al., "Variability and trend in the hydrology of the Yangtze River, China: annual precipitation and runoff," Journal of Hydrology, vol. 513, pp. 403-412, 2014.

[11] L. Q. Liang, L. J. Li, and Q. Liu, "Precipitation variability in Northeast China from 1961 to 2008," Journal of Hydrology, vol. 404, no. 1-2, pp. 67-76, 2011.

[12] M. F. Hutchinson, "Interpolation of rainfall data with thin plate smoothing splines. Part I: two dimensional smoothing of data with short range correlation," Journal of Geographic Information and Decision Analysis, vol. 2, no. 2, pp. 139-151, 1998.

[13] M. F. Hutchinson, "Interpolation of rainfall data with thin plate smoothing splines. Part II: analysis of topographic dependence," Journal of Geographic Information and Decision Analysis, vol. 2, no. 2, pp. 152-167, 1998.

[14] National Meteorological Information Center, Assessment Report of China's Ground Precipitation $0.5^{\circ} \times 0.5^{\circ}$ Gridded Dataset (V2.0), National Meteorological Information Center, Assessment Report of China's Ground, Beijing, China, 2012.

[15] C. Piani, G. P. Weedon, M. Best et al., "Statistical bias correction of global simulated daily precipitation and temperature for the application of hydrological models," Journal of Hydrology, vol. 395, no. 3-4, pp. 199-215, 2010.

[16] S. Hagemann, C. Chen, J. O. Haerter, J. Heinke, D. Gerten, and C. Piani, "Impact of a statistical bias correction on the projected hydrological changes obtained from three GCMs and two hydrology models," Journal of Hydrometeorology, vol. 12, no. 4, pp. 556-578, 2011.

[17] H. B. Mann, "Nonparametric tests against trend," Econometrica, vol. 13, pp. 245-259, 1945.

[18] K. H. Hamed, "Exact distribution of the Mann-Kendall trend test statistic for persistent data," Journal of Hydrology, vol. 365, no. 1-2, pp. 86-94, 2009.

[19] Y. Tian, Y.-P. Xu, M. J. Booij, S. Lin, Q. Zhang, and Z. Lou, "Detection of trends in precipitation extremes in Zhejiang, east
China," Theoretical and Applied Climatology, vol. 107, no. 1-2, pp. 201-210, 2012.

[20] W. Wang, X. Chen, P. Shi, and P. H. A. J. M. Van Gelder, "Detecting changes in extreme precipitation and extreme streamflow in the Dongjiang River Basin in southern China," Hydrology \& Earth System Sciences, vol. 12, no. 1, pp. 207-221, 2008.

[21] H. Wang, D. H. Yan, D. Y. Qin et al., "A study of the spatial shift of $400 \mathrm{~mm}$-rainfall contours in the Yellow River Basin during recent 50 years," Advances in Earth Science, vol. 20, no. 6, pp. 649-655, 2005.

[22] J. Feng, D. H. Yan, C. Z. Li, F. Yu, and C. Zhang, "Assessing the impact of climatic factors on potential evapotranspiration in droughts in North China," Quaternary International, vol. 336, pp. 6-12, 2014.

[23] L. Z. Zhang, M. Li, Z. F. Wu et al., "Vegetation cover change and its mechanism in northeast China based on SPOT/NDVI data," Journal of Arid Land Resources and Environment, vol. 25, no. 1, pp. 171-175, 2011 (Chinese). 

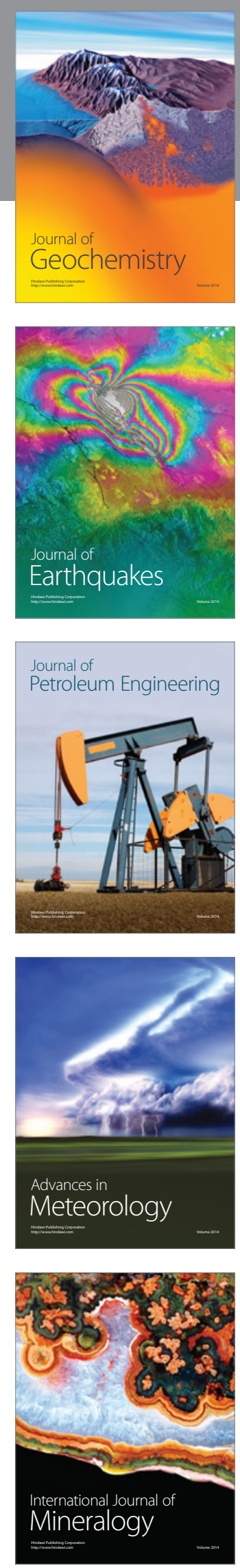
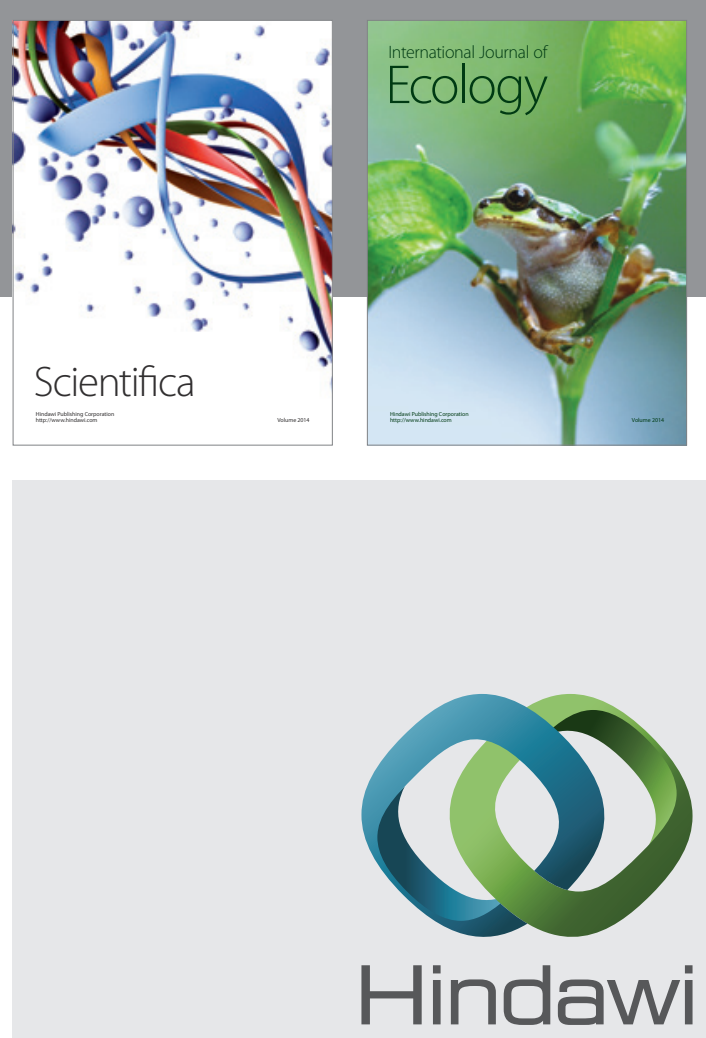

Submit your manuscripts at

http://www.hindawi.com
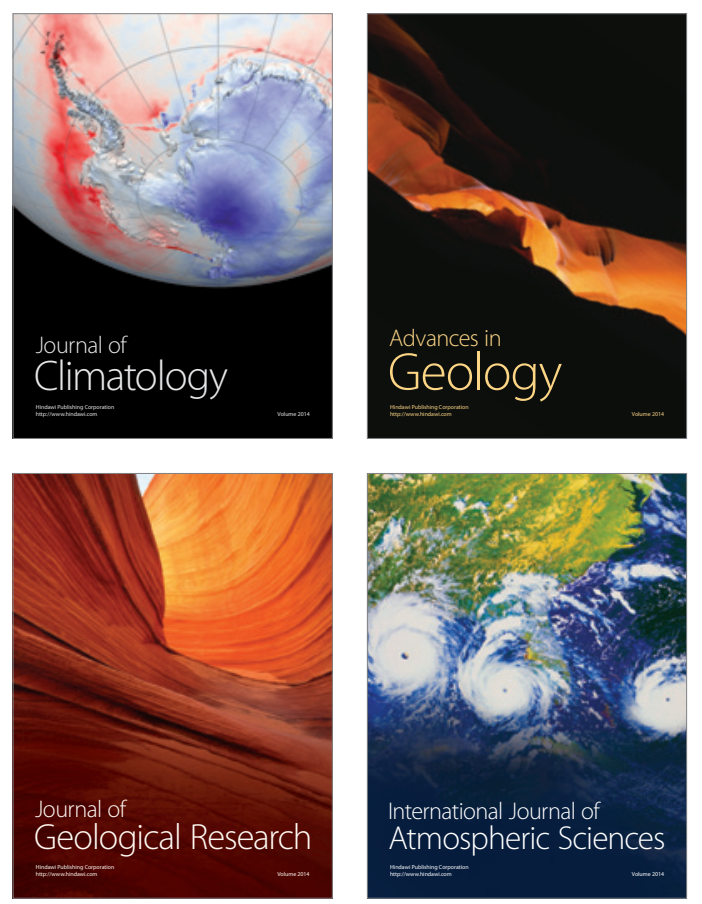

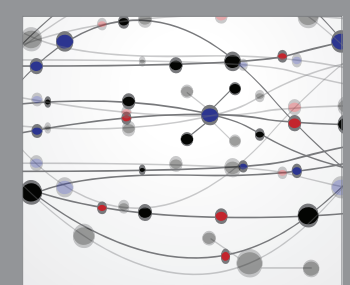

The Scientific

\section{World Journal}
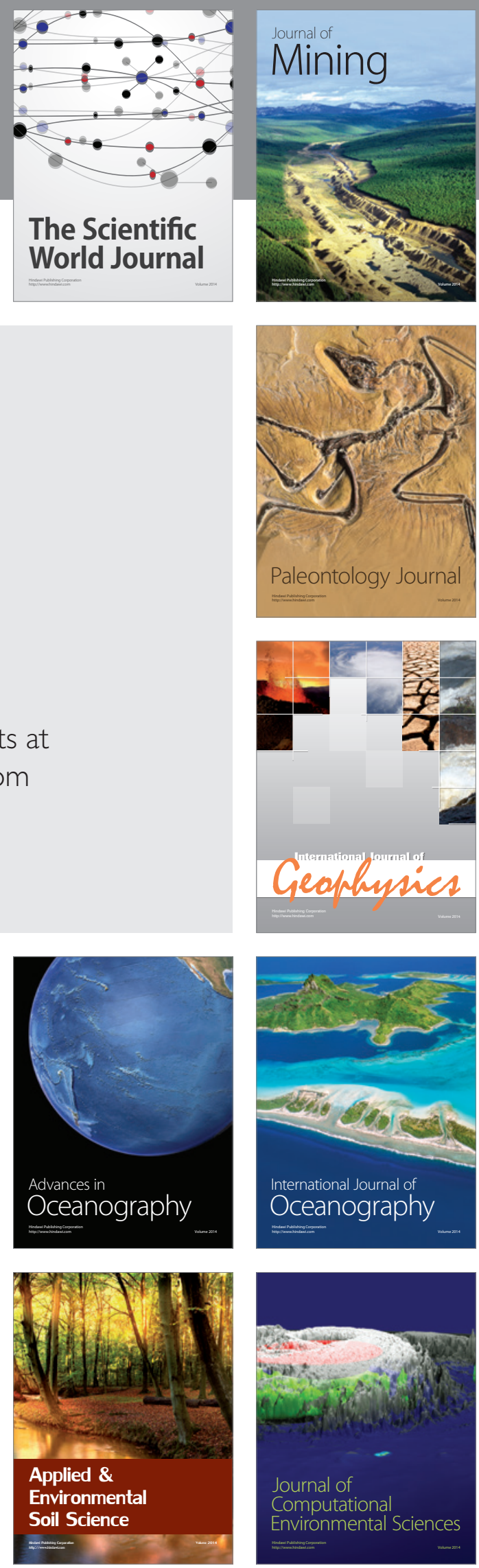